\title{
A novel relationship between ants and a leafhopper (Hymenoptera: Formicidae; Hemiptera: Cicadellidae)
}

\author{
Florian M. STEINER ${ }^{1}$, Birgit C. SCHLICK-STEINER ${ }^{1}$, Werner HOLZINGER ${ }^{2}$, Christian KOMPOSCH ${ }^{2}$, \\ Sylvie PAZOUTOVA ${ }^{3}$, MatTHias SANETRA ${ }^{4}$ and ERHARd CHRISTIAN ${ }^{1}$ \\ ${ }^{1}$ Institute of Zoology, Department of Integrative Biology, and Institute of Forest Entomology, Forest Pathology and Forest \\ Protection, Department of Forest and Soil Sciences, University of Natural Resources and Applied Life Sciences Vienna, \\ Gregor-Mendel-Straße 33, A-1180 Wien, Austria; e-mail: h9304696@edv1.boku.ac.at \\ ${ }^{2}$ Ökoteam - Institute of Faunistics and Animal Ecology, Bergmanngasse 22, A-8010 Graz, Austria; \\ e-mail: oekoteam@sime.com \\ ${ }^{3}$ Institute of Microbiology, Czech Academy of Sciences, Vídeňská 1083, 14220 Prague 4, Czech Republic; \\ e-mail: pazouto@biomed.cas.cz \\ ${ }^{4}$ Zoology and Evolutionary Biology, University of Konstanz, Universitätsstraße 10, D-78457 Konstanz, Germany
}

Key words. Araneae, Auchenorrhyncha, ant-leafhopper relationship, honeydew, insect-insect interactions, mutualism, Cicadellidae, Formicidae, Balclutha punctata, Calamagrostis epigejos

\begin{abstract}
Ten ant species (Hymenoptera: Formicidae) from three subfamilies feed on honeydew excreted by nymphs of the leafhopper Balclutha punctata (Hemiptera: Cicadellidae). This relationship is facultative for the partners. Preliminary field observations suggest a mutualistic interaction that represents an intermediate stage in the spectrum of formicid-hemipteran mutualisms. Behavioural adaptations of the leafhopper (no escape reaction) and the ants (no predation of leafhoppers, protection from spiders) are evident, but characters of advanced facultative mutualism such as physical contact between the partners or ant-triggered excretion of honeydew were not observed.
\end{abstract}

\section{INTRODUCTION}

Ants are major ecological players (Hölldobler \& Wilson, 1990), interacting with an estimated 100,000 insect species (Schönrogge et al., 2000). Among these are a wealth of plant sap-sucking Hemiptera whose production of honeydew often exceeds several times the insect body mass per hour (Larsen et al., 1992). As honeydew contains substances vital to ants such as sugars, amino acids, amides, proteins and vitamins, a variety of ant-hemipteran relationships have evolved (Way, 1963; Delabie, 2001). The relationships frequently are mutualistic, i.e. reciprocally beneficial (Herre et al., 1999). Ants benefit from a concentrated and reliable food source, Hemiptera from protection against enemies and from honeydew removal, which prevents hemipteran eggs and nymphs from suffocation and mould growth. This leads to increased food uptake and larger hemipteran populations (Way, 1963; Stadler et al., 2001).

Ant-hemipteran relationships provide good models for the study of mutualism (cf. DelClaro \& Oliveira, 1999; Delabie, 2001), and there is a rich literature on such relationships involving aphids and mealybugs (e.g. Way, 1963; Gullan, 1997; Delabie, 2001). Those with leafhoppers (Auchenorrhyncha: Cicadellidae s.1.), however, are rarely addressed and are reported mainly from tropical regions (e.g. Dietrich \& McKamey, 1990; Moya-Raygoza \& Nault, 2000; Shcherbakov et al., 2000). Here we report on a novel ant-cicadellid relationship between European species: the case of Balclutha punctata (Fabricius, 1775). Starting from the observation of ants visiting grass-spikes (Fig. 1A-C) we present first evidence of the interaction, assess potential benefits to and adaptations of the partners and place the phenomenon within the continuum of ant-hemipteran relationships, ranging from antagonistic to mutualistic and from primitive to advanced.

\section{METHODS}

Field studies were carried out between late June and late August 2001-2003 in a Central European grassland habitat (St.

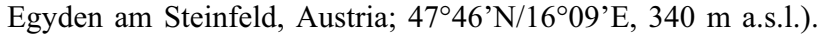
Ants visiting spikes of the dominant wood small-reed Calamagrostis epigejos (L.) Roth (Fig. 1A-C) were collected from the spikes and determined using Seifert (1996). To assess whether ants imbibe fungal exudates when on the grass spikes, the crops of ants were dissected. The crop contents of six ants and ten honeydew droplets from Calamagrostis spikes were inspected for fungi using light microscopy (magnification $1000 \times$ ).

On nine occasions, at varying times of the day and for one to three hours each, ant behaviour on the spikes was qualitatively observed in the field using magnifying glasses (magnification $2-20 \times$ ), especially food uptake and interactions with other arthropods. A total of about 400 ants were observed. Additionally, ant behaviour on spikes was recorded in the laboratory using a Canovision EX2Hi $8 \mathrm{~mm}$ Video Camcorder with a 100 $\mathrm{mm}$ macro lens.

In 2003 ten ant-visited spikes were harvested, singly sealed in plastic bags and inspected for leafhoppers in the laboratory. Adult and nymphal leafhoppers were counted and identified using Ossiannilsson (1983) and Vilbaste (1982). As spiders were frequently observed preying on leafhopper nymphs on spikes without ants, 100 spikes with and 100 spikes without visiting ants were examined in the field. Spiders were collected and determined using Roberts (1995), Wolf (1991) and Zabka (1997).

Cultures of fungi from two ant-visited Calamagrostis spikes were grown on malt extract agar. Fungal species were determined according to mycelial morphology and shape of conidia (both washed from spikes and grown in the culture) following Barnett \& Hunter (1998). 
To determine whether the visiting of Calamagrostis spikes by ants is a local peculiarity and ant attendance correlates with the presence of leafhoppers inside the spikes, we investigated six additional stands of Calamagrostis epigejos within $70 \mathrm{~km}$ of the St. Egyden stand, each once in July 2003. Ants and leafhoppers were sampled as indicated above.

\section{RESULTS}

Ten ant species of three subfamilies were observed visiting spikes of Calamagrostis epigejos at St. Egyden. Myrmicinae: Myrmica schencki Viereck, 1903, M. sabuleti Meinert, 1861 (Fig. 1A); Dolichoderinae: Tapinoma erraticum (Latreille, 1798); Formicinae: Camponotus ligniperda (Latreille, 1802), C. vagus (Scopoli, 1763) (Fig. 1B), Lasius alienus (Förster, 1850), Formica cunicularia Latreille, 1798, F. fusca Linnaeus, 1758, $F$. lusatica Seifert, 1997 and F. sanguinea Latreille, 1798 (Fig. 1C).

In an area of one hectare thousands of ants were observed on the spikes at any time during the day from late June to late August. Without exception, ants were slowly running up and down the spikes, frequently stopping and inserting their heads into the spikes (Fig. 1A-C). Often several ant species visited a single spike simultaneously or in succession.

Examination of the interior of ant-visited spikes revealed nymphal aggregations of the leafhopper Balclutha punctata (Fabricius, 1775) sensu Wagner, 1939 nec Blocker, 1967 (Auchenorrhyncha: Cicadellidae) on the stem (Fig. 1D). Nymphs of this cicadellid feed on phloem sap (R. Remane, pers. comm.). Aggregations comprised $59.1 \pm 31.4$ (SD) nymphs per spike ( $\mathrm{n}=10$ spikes with ant traffic), but only occasionally adults. The inflorescences always contained numerous droplets of a clear liquid (Fig. E, F). Both in the field and in the laboratory, B. punctata nymphs were observed to slowly excrete droplets of c. $0.2 \mathrm{~mm}$ in diameter, which remained inside the inflorescence (Fig. E). When a nymph remained in one place for some time, several droplets fused into a bigger drop of c. 1.0 $\mathrm{mm}$. In the field, a total of 9 workers of three ant species (Camponotus vagus, Formica fusca, $F$. sanguinea) were observed imbibing droplets, without interacting with the leafhoppers. In the laboratory five Camponotus vagus workers were observed doing this. Ants neither fed on B. punctata nymphs nor transferred them.

To exclude the possibility that the droplets imbibed by ants were the sugary exudate of the ergot fungus Claviceps purpurea Tulasne, 1853 (taken up by insects: Staeger, 1908), cultures of fungi from Calamagrostis epigejos were grown. Three dematiaceous species common on grasses, but not excreting liquids, were detected (Cercospora sp., Drechslera sp., Alternaria sp.). Fungal spores were present neither in droplets nor in ant crops.

No other arthropods were found on ant-visited spikes $(\mathrm{n}=100$ spikes). On spikes unattended by ants $(\mathrm{n}=100$ spikes) a total of 17 spiders was found ( $0-1$ spider per spike), some while feeding on B. punctata nymphs. Nine species of spiders were recorded (number of individuals in parentheses). Araneidae: Neoscona adianta (Walckenaer, 1802) (2 ff), cf. Zilla diodia Walckenaer, 1802 (1 juv.); Oxyopidae: Oxyopes ramosus (Martini \& Goeze, 1778) (2 ff); Clubionidae: Cheiracanthium punctorium (Villers, 1789) (1 f, 1 juv.); Philodromidae: Thanatus cf. formicinus
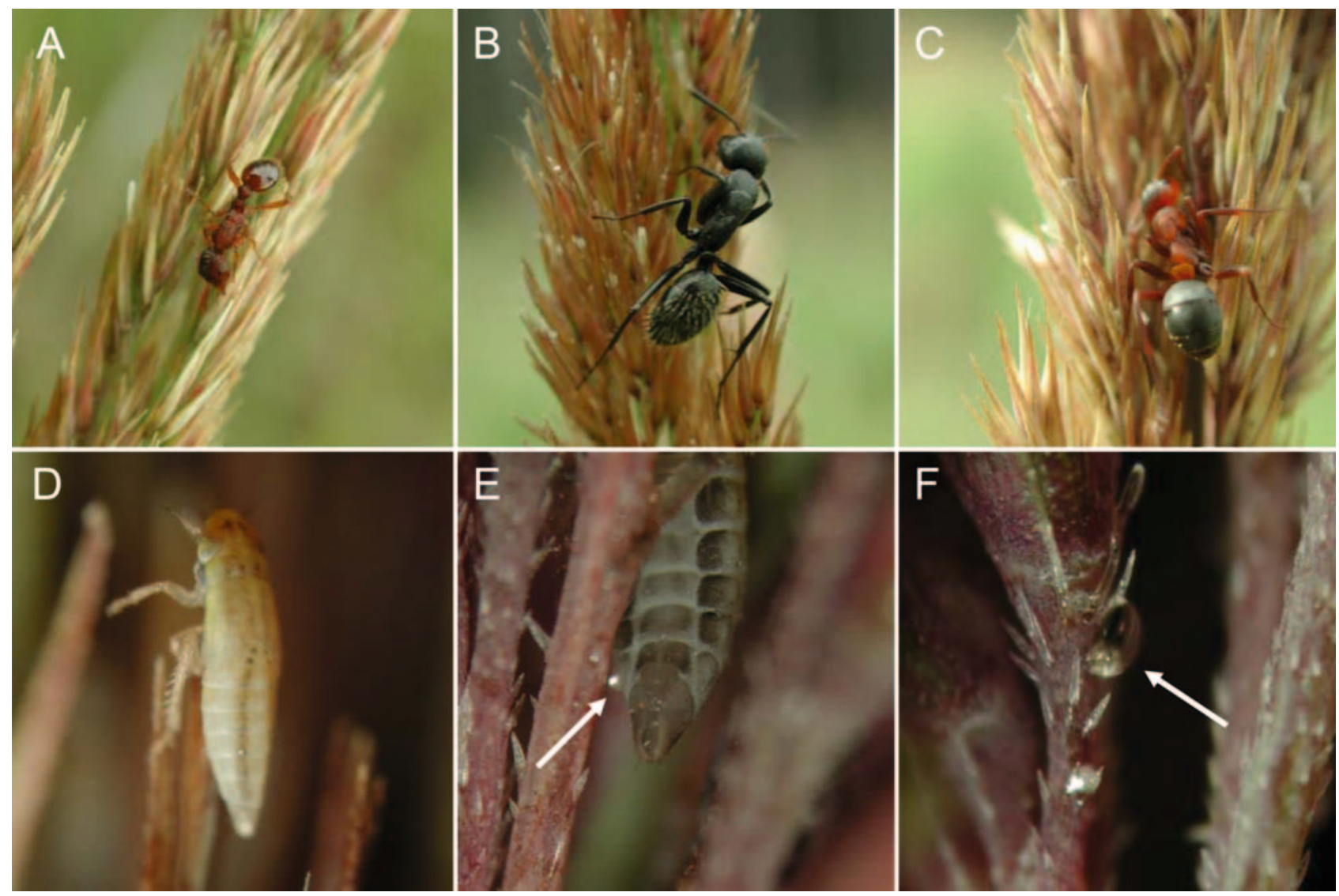

Fig. 1. Workers of the ants (A) Myrmica sabuleti, (B) Camponotus vagus and (C) Formica sanguinea inserting their heads between the spikelets of Calamagrostis epigejos spikes; (D) nymph of the leafhopper Balclutha punctata inside a C. epigejos spike, (E) anus of B. punctata viewed from below, after depositing a honeydew droplet (arrow), (F) honeydew droplet (arrow) inside a spike. 
(Clerck, 1757) (1 juv.); Thomisidae: Misumena vatia (Clerck, 1757) (1 juv.); Xysticus sp. (5 juv.); Salticidae: Heliophanus cf. cupreus (Walckenaer, 1802) (2 juv.) and Heliophanus flavipes (Hahn, 1832) (1 f). All are hunters and potential predators of leafhopper nymphs, with the exception of the 3 araneid orbweavers, which are potential predators of adult leafhoppers (Nyffeler \& Benz, 1989; Nyffeler et al., 1992). Nyffeler (1999) has shown that the percentage of Homoptera in the diet of spiders is about $10 \%$ for hunters and $33 \%$ for web-weavers (up to $31 \%$ Auchenorrhyncha).

At five of six other stands of C. epigejos no spike-visiting ants were observed. Leafhopper density was lower than in St. Egyden: $4.5 \pm 3.7$ nymphs per spike $(\mathrm{n}=$ a total of 19 spikes with at least one nymph per spike, taken from the five sites without ant attendance). Sometimes nymphs of the related species Balclutha calamagrostis Ossiannilsson, 1961 as well as aphids occurred together with $B$. punctata nymphs. Spikevisiting ants were recorded at only one of these sites, $65 \mathrm{~km}$ from St. Egyden.

Irrespective of ant attendance, $B$. punctata nymphs were never parasitized by parasitoids (all nymphs inspected). The host plants of $B$. punctata, visited by ants or not, always appeared healthy.

Every year in late August, when the spikes of C. epigejos were dry and no leafhopper nymphs remained, ants stopped visiting the spikes.

\section{DISCUSSION}

Our preliminary observations suggest that the relationship is facultative for the ants. All ten formicid species observed at $B$. punctata aggregations are known to collect honeydew (Seifert, 1996), yet are not specialized exploiters of this resource (Fritz, 1982). The absence of ants on spikes hosting B. punctata nymphs at five sites indicates that the relationship is facultative for the leafhoppers as well. Considering the higher number of nymphs per spike in the St. Egyden population compared with the five populations not attended by ants $(59.1 \pm 31.4$ vs. $4.5 \pm$ 3.7 nymphs per spike), we assume, despite the small sample size, that ant attendance increases leafhoppers' fitness. Calamagrostis epigejos appeared healthy both in stands with and without ant attendance, which indicates that $B$. punctata uses the host plant sustainably. This contrasts with the neotropical obligate ant-mutualist Dalbulus quinquenotatus DeLong \& Nault. Ants regulate populations of this leafhopper by removing nymphs and adults. Without ant attendance, the nymphal aggregations quickly kill their host (Moya-Raygoza \& Nault, 2000).

$B$. punctata nymphs are gregarious and hemisessile, characters that enhance the effectiveness of ants in providing protection from natural enemies (Larsen et al., 1992). Another feature of the leafhoppers makes attendance profitable for ants. In contrast to most other hemipteran sap-suckers (Larsen et al., 1992), B. punctata nymphs do not eject or flick honeydew away. This may be an adaptation to the little space inside spikes, as the measured deposition and subsequent fusion of droplets prevent the spike and other nymphs from being covered in honeydew. On the other hand, the concentration of honeydew droplets inside the spikes provides a rich and predictable food resource for ants. Thus, foraging becomes more effective compared with other (non-attended) Hemiptera, whose honeydew drops to the ground and may eventually be scavenged by ants (Carver et al., 1991).

Several characters make the observed relationship interesting with respect to the evolution of ant-hemipteran mutualisms:

(1) Ants were not observed to prey on the leafhoppers. This is interpreted as a behavioural adaptation because all ant species in question are facultative predators (Seifert, 1996) and, according to current evidence, predation is involved in the early stages of ant-hemipteran mutualisms (Stadler \& Dixon, 1999).

(2) B. punctata nymphs did not exhibit escape reactions. While this is also true for Dalbulus quinquenotatus, other nonmutualistic Dalbulus species evade ants. Since B. punctata nymphs are able to jump (Dietrich \& MacKamey, 1990; Shcherbakov et al., 2000), the absence of an escape reaction is definitely a behavioural adaptation.

(3) Ants seem to protect the leafhoppers from arthropod predation, either actively or through their mere presence on the grass spikes. While in other Auchenorrhyncha parasitoids are an important mortality factor and ant attendance is known to reduce parasitization (Dejean et al., 1996), the main benefit for B. punctata nymphs could be protection against predatory spiders, like in membracids (Cushman \& Whitham, 1989).

(4) The excretion of honeydew droplets was not found to be adapted to ant attendance. Other ant-mutualists offer honeydew directly to ants, with the droplets remaining on the anus for a prolonged period (Hölldobler \& Wilson, 1990; Larsen et al., 1992). As this behavioural adaptation increases the efficiency of the relationship, we think that the behaviour of B. punctata is more primitive. The situation in Peregrinus maidis (Ashmead, 1890) (Delphacidae), where ants lick droplets both from the substrate and directly from the anus of the honeydew producer (Dejean et al., 1996), could represent an advanced stage, surpassed by species such as Dalbulus quinquenotatus, which offer honeydew to ants without exception.

(5) No physical contact between ants and leafhopper nymphs was observed. Antennation and subsequent excretion of a honeydew droplet would increase the efficiency of the relationship (Hölldobler \& Wilson, 1990; Larsen et al., 1992).

Characters (1)-(3) make the relationship appear advanced compared with unspecialised ant-hemipteran interactions (Larsen et al., 1992; Delabie, 2001), while characters (4)-(5) suggest that it is not as highly evolved as other ant-hemipteran relationships (Way, 1963; Larsen et al., 1992; Delabie, 2001; Stadler \& Dixon, 1999). The relationship between Balclutha punctata and ants could be an intermediate stage in the evolution of mutualism between ants and Hemiptera.

ACKNOWLEDGEMENTS. Our thanks go to H. Anglberger, B. Becker, A. Buschinger, C. Dietrich, D. Dmitriev, P.J. Gullan, H. Höttinger, H. Konrad, T. Ljubomirov, J. Martin, K. Moder, M. Nyffeler, R. Rakitov, R. Remane, M. Stachowitsch, M. Webb, $\mathrm{M}$. Wilson and two anonymous referees.

\section{REFERENCES}

BARNETT H.L. \& Hunter B.B. 1998: Illustrated Genera of Imperfect Fungi, 4th ed. APS Press, St. Paul, Minnesota, 218 pp.

Carver M., Gross G.F. \& Woodward T.E. 1991: Hemiptera (bugs, leafhoppers, cicadas, aphids, scale insects etc.). In Commonwealth Scientific and Industrial Research Organisation (ed.): The Insects of Australia. A Textbook for Students and Research Workers. Melbourne University Press, Carlton, pp. 429-515.

Cushman J.H. \& Whitham T.G. 1989: Conditional mutualism in a membracid-ant association: temporal, age-specific, and density-dependent effects. Ecology 70: 1040-1047.

Dejean A., Ngnegueu P.R. \& Bourgoin T. 1996: Trophobiosis between ants and Peregrinus maidis (Hemiptera, Fulgoromorpha, Delphacidae). Sociobiology 28: 111-120.

Del-Claro K. \& Oliveira P.S. 1999: Ant-Homoptera interactions in a neotropical savanna: the honeydew-producing treehopper, Guayaquila xiphias (Membracidae), and its associated 
ant fauna on Didymopanax vinosum (Araliacea). Biotropica 31: $135-144$.

DelabiE J.H.C. 2001: Trophobiosis between Formicidae and Hemiptera (Sternorrhyncha and Auchenorrhyncha): an overview. Neotrop. Entomol. 30: 501-516.

Dietrich C.H. \& McKamey S.H. 1990: Three new idiocerine leafhoppers (Homoptera: Cicadellidae) from Guayana with notes on ant-mutualism and subsociality. Proc. Entomol. Soc. Wash. 92: 214-223.

FRITZ R.S. 1982: An ant-treehopper mutualism: effects of Formica subsericea on the survival of Vanduzea arquata. Ecol. Entomol. 7: 267-276.

Gullan P.J. 1997: Relationships with ants. In Ben-Dov Y. \& Hodgson C.J. (eds): Soft Scale Insects - Their Biology, Natural Enemies and Control. Elsevier, Dordrecht, pp. 351-373.

Herre E.A., Knowlton N., Mueller U.G. \& Rehner S.A. 1999: The evolution of mutualisms: exploring the paths between conflict and cooperation. Trends Ecol. Evol. 14: 49-53.

Hölldobler B. \& Wilson E.O. 1990: The Ants. The Belknap Press of Harvard University Press, Cambridge, MA, 732 pp.

Larsen K.J., Heady S.E. \& Nault L.R. 1992: Influence of ants (Hymenoptera: Formicidae) on honeydew excretion and escape behaviors in a myrmecophile, Dalbulus quinquenotatus (Homoptera: Cicadellidae), and its congeners. J. Insect Behav. 5: 109-122.

Moya-Raygoza G. \& Nault L.R. 2000: Obligatory mutualism between Dalbulus quinquenotatus (Homoptera: Cicadellidae) and attendant ants. Ann. Entomol. Soc. Am. 93: 929-940.

NyfFELER M. 1999: Prey selection of spiders in the field. $J$. Arachnol. 27: 217-324.

Nyffeler M. \& Benz G. 1989: Foraging ecology and predatory importance of a guild of orb-weaving spiders in a grassland habitat. J. Appl. Entomol. 107: 166-184.

Nyffeler M., Dean D.A. \& Sterling W.L. 1992: Diets, feeding specialization, and predatory role of two lynx spiders, Oxyopes salticus and Peucetia viridans (Araneae: Oxyopidae), in a Texas cotton agroecosystem. Envir. Entomol. 21: 1457-1465.

OssianniLsson F. 1983: The Auchenorrhyncha (Homoptera) of Fennoscandia and Denmark. Part 3: The family Cicadellidae: Deltocephalinae, catalogue, literature and index. Fauna Entomol. Scand. 7: 594-979.

RoBerts M.J. 1995: Collins Field Guide. Spiders of Britain \& Northern Europe. Harper Collins Publisher, London, 383 pp.

Schönrogge K., Wardlaw J.C., Thomas J.A. \& Elmes G.W. 2000: Polymorphic growth rates in myrmecophilous insects. Proc. R. Soc. Lond. (B) 267: 771-777.

SEIFERT B. 1996: Ameisen: beobachten, bestimmen. Naturbuch Verlag, Augsburg, 351 pp.

Shcherbakov D.E., Fletcher M.J. \& Day M.F. 2000: Ant attendance and nocturnal feeding of the leafhopper Smicrocotis obscura Kirkaldy (Hemiptera: Cicadellidae: Ledrinae). Austral. Entomol. 27: 39-43.

Stadler B. \& Dixon A.F.G. 1999: Ant attendance in aphids: why different degrees of myrmecophily? Ecol. Entomol. 24: 363-369.

Stadler B., Fiedler K., Kawecki T.J. \& Weisser W.W. 2001: Costs and benefits for phytophagous myrmecophiles: when ants are not always available. Oikos 92: 467-478.

Staeger R. 1908: Zur Biologie des Mutterkorns. Zentbl. Bakt. Parasitkde Infektionskrankh. (II) 20: 272-279.

Vilbaste J. 1982: Preliminary key for the identification of the nymphs of North European Homoptera Cicadinea. II. Cicadelloidea. Ann. Zool. Fenn. 19: 1-20.

WAY M.J. 1963: Mutualism between ants and honeydewproducing homoptera. Annu. Rev. Entomol. 8: 307-344.

Wolf A. 1991: Cheiracanthium. In Heimer S. \& Nentwig W. (eds.): Spinnen Mitteleuropas. Verlag Paul Parey, Berlin \& Hamburg, pp. 396-398, plates 181-182.

Zaвka M. 1997: Salticidae (Arachnida: Araneae). Fauna Polon. 19: $1-188$.

Received January 26, 2004; revised June 21, 2004; accepted July 30, 2004 